\title{
DESENHO INDUSTRIAL E INDICAÇÕES GEOGRÁFICAS NA ÓTICA DA LEI DE PROPRIEDADE INDUSTRIAL BRASILEIRA
}

\author{
Germana Fonseca Crespo Garcia ${ }^{1}$
}

\section{RESUMO}

Este artigo faz um estudo da proteção do desenho industrial e das indicações geográficas de acordo com a lei de propriedade industrial brasileira. Em um primeiro momento trata dos requisitos para proteção, do procedimento, da vigência entre outros aspectos do desenho industrial. Na seqüência faz uma análise sobre as indicações geográficas abordando a denominação, o pedido de registro, o processamento do pedido e exemplos de casos brasileiros. E ao fim busca-se relacionar o uso das indicações geográficas com os produtos feitos pelas populações tradicionais, como uma maneira de agregar valor aos produtos, respeitando seu modo de produção.

\section{ABSTRACT}

This article is about the protecion of industrial design and geographical indications according to industrial property law. In a first moment, the analysis of the requirement for protecion, proceeding, validity of the industrial design. After, a study about denomination, request of registration, proceeding and exemple of Brazilian cases of geographical indications. And the use of this like a manner of increase the value of the poducts made by tradicional populations, respecting their production way.

Indicadores: DESENHO INDUSTRIAL - INDICAÇÕES GEOGRÁFICAS - LEI DE PROPRIEDADE INDUSTRIAL.

\footnotetext{
${ }^{1}$ Graduada em Direito pela Universidade Federal do Paraná. Pesquisadora do Núcleo de Estudos em Direito Internacional da UFPR.
}

Revista Brasileira de Direito Internacional, Curitiba, v.4, n.4, jul./dez.2006 
Key-words: INDUSTRIAL DESIGN - GEOGRAPHICAL INDICATIONS INDUSTRIAL PROPERTY LAW.

\section{INTRODUÇÃO}

A Lei de Propriedade Industrial, Lei $n^{\circ}$ 9.279, de 14 de maio de 1996, regula atualmente o tema em substituição ao antigo Código da Propriedade Industrial, Lei $\mathrm{n}^{\circ} 5.772$, de 21 de dezembro de 1971, tutelando tanto os desenhos industriais quanto as indicações geográficas.

O presente artigo tem por escopo analisar o tratamento jurídico nacional desses dois institutos, conforme disposto na Lei de Propriedade Industrial.

Estruturalmente o artigo está dividido em duas partes. A primeira, referente ao desenho industrial abordando, entre outros aspectos, quais os requisitos para se obter a proteção, o procedimento, o exame de mérito e algumas diferenças fundamentais em relação a lei antiga. A segunda parte traz um estudo sobre as indicações geográficas, relatando quais os requisitos para se pedir um registro, o procedimento, os limites da proteção, entre outros pontos. Sempre procurando trazer um conhecimento técnico e crítico sobre o tema.

\section{DESENHO INDUSTRIAL}

\subsection{NOÇÕES PRELIMINARES. DENOMINAÇÃO}

A inclusão do Título III - Dos Desenhos Industriais na atual Lei $n^{\circ}$ 9.279/1996 se constitui um avanço em relação à legislação precedente (Lei n $5.772 / 1971$ ). A proteção dos desenhos industriais migrou da categoria de patente para uma categoria própria de registro, visando trazer maior celeridade ao processo.

Revista Brasileira de Direito Internacional, Curitiba, v.4, n.4, jul./dez.2006 
Outra inovação da atual lei brasileira de propriedade industrial foi a unificação dos conceitos de modelo industrial ${ }^{2}$ e desenho industrial ${ }^{3}$ em um único princípio: desenho industrial.

Com base nessas informações percebe-se que somente a invenção e o modelo de utilidade são passíveis de patente, ao passo que o desenho industrial é registrável.

Nessa altura se faz necessário diferenciar a invenção, do modelo de utilidade e do desenho industrial, para melhor caracterizar o objeto de estudo, o desenho industrial.

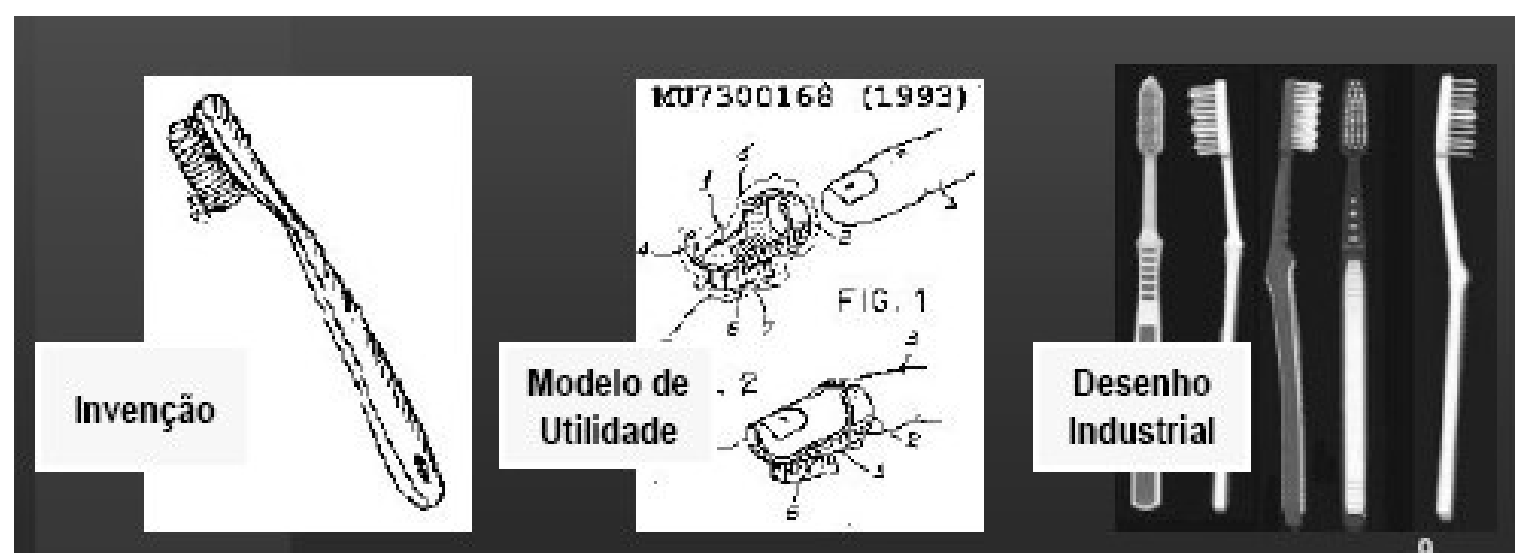

Fig. 1 Ilustração diferenciando invenção, modelo de utilidade e desenho industrial. A invenção é algo novo, que não existia anteriormente, assim como quando a escova de dente foi inventada. A escova aperfeiçoada para ser usada por bebes ou cachorros é um exemplo de modelo de utilidade. Os novos modelos de escova, com formatos variados, trazendo ao produto um novo design, caracterizam o desenho industrial.

(Fonte: Escritório de propriedade industrial BHERING ADVOGADOS, filial Curitiba)

A invenção caracteriza-se como uma coisa nova criada no campo da ciência ou da tecnologia, para ser patenteável deve atender aos requisitos de novidade, atividade inventiva e aplicação industrial ${ }^{4}$.

\footnotetext{
${ }^{2}$ Modelo industrial, para a Lei $n^{\circ} 5.772 / 1971$, "correspondia a um bem imaterial que constituía um meio de expressão da criatividade humana e que se exteriorizava pela forma plástica tridimensional de um objeto suscetível de utilização industrial". (DI BLASI JUNIOR, Clésio Gabriel; GARCIA, Mario Augusto Soerensen; MENDES, Paulo Parente Marques. A propriedade industrial: os sistemas de marcas, patentes e desenhos industriais a partir da Lei $n^{\circ} 9.279$, de 14 de maio de 1996. Rio de Janeiro: Forense, 1996, p. 189)

${ }^{3}$ Desenho industrial, na ótica da Lei $n^{\circ} 5.772 / 1971$, "era um bem imaterial constituído pela disposição de linhas e cores em um plano bidimensional, referente à ornamentação de um produto e suscetível de utilização industrial, realizando combinações originais". (DI BLASI JUNIOR, Clésio Gabriel; GARCIA, Mario Augusto Soerensen; MENDES, Paulo Parente Marques, obra citada, p. 189)

${ }^{4}$ Art. $8^{\circ}$ da Lei ${ }^{\circ} 9.279 / 96$.
} 
O modelo de utilidade é o objeto de uso prático, ou parte deste, suscetível de aplicação industrial, que apresente nova forma ou disposição, envolvendo ato inventivo, que resulte em melhoria no seu uso ou em sua fabricação ${ }^{5}$. Via de regra, o modelo de utilidade está restrito a aperfeiçoamentos ou melhoramentos em ferramentas, equipamentos ou peças. Um exemplo é a escova aperfeiçoada para ser usada por bebês ou cachorros.

O desenho industrial traz ao produto um novo design, é uma "obra de arte aplicada" . Ou, consoante o art. 95 da Lei $n^{\circ} 9.279 / 96$, desenho industrial é a forma plástica ornamental de um objeto ou o conjunto ornamental de linhas e cores que possa ser aplicado a um produto, proporcionando resultado visual novo e original na sua configuração externa e que possa servir de tipo de fabricação industrial.

\subsection{REQUISITOS DE PROTEÇÃO: NOVIDADE E ORIGINALIDADE}

O desenho industrial é novo quando não compreendido no estado da técnica. O estado da técnica constitui tudo aquilo tornado acessível ao público antes da data do depósito do pedido de registro no Brasil ou no exterior. Para aferição da novidade, o conteúdo completo de pedido de patente ou de registro depositado no Brasil, e ainda não publicado, será incluído no estado da técnica a partir da data de depósito, ou da prioridade reivindicada, desde que venha a ser publicado ${ }^{7}$.

O dispositivo visa impedir que dois registros sejam concedidos para objetos idênticos.

Como exceção ao princípio da novidade, considera-se excluído do estado da técnica o desenho industrial cuja divulgação tenha ocorrido durante os cento e oitenta dias que precederem a data do depósito ou da prioridade reivindicada, se promovida: pelo autor; pelo Instituto Nacional de Propriedade Intelectual (INPI), nos casos previstos na lei; ou por terceiros, com base em

\footnotetext{
${ }^{5}$ Art. $9^{\circ}$ da Lei $n^{\circ} 9.279 / 96$.

${ }^{6}$ BARBOSA, Denis Borges. Proteção dos Modelos de Utilidade e do Designs. Disponível via internet http://denisbarbosa.addr.com/127.doc. Acesso em 29 de junho de 2006.

${ }^{7}$ Art. $96, \S 1^{\circ}$ e $\S 2^{\circ}$ da Lei $n^{\circ} 9.279 / 96$.
}

Revista Brasileira de Direito Internacional, Curitiba, v.4, n.4, jul./dez.2006 
informações obtidas diretamente ou indiretamente do autor ou em decorrência de atos por este realizado ${ }^{8}$.

O desenho industrial, segundo o art. 97 da Lei $n^{\circ} 9.279 / 96$, é considerado original quando dele resulte uma configuração visual distintiva, em relação a outros objetos anteriores. O dispositivo ainda prevê que o resultado visual original poderá ser decorrente da combinação de elementos conhecidos. Aduz Newton Silveira que :

“(..) a originalidade é condição tanto para a proteção das invenções, quanto
das obras artísticas, podendo-se dizer que nas obras de arte a originalidade se
refere à forma considerada em si mesma, enquanto que para os modelos e
desenhos industriais a forma em si pode não ser original, desde que o seja a
sua aplicação, isto é, a originalidade neste caso consistiria na associação
original de uma determinada forma a um determinado produto industrial."

Portanto, além de o desenho industrial ser novo, é mister que sua configuração visual seja percebida como distintiva; assim, "parece razoável supor que o desenho proposto não possa ser confundido com objetos conhecidos quando colocados lado a lado"10.

O art. 98 da Lei de Propriedade Industrial brasileira exclui da proteção por registro de desenho industrial qualquer obra de caráter puramente artístico; ou nas palavras do autor Newton Silveira: "caso determinada criação de forma tenha caráter puramente artístico, não poderá ser objeto de uma patente de modelo ou desenho industrial (...). Por outro lado, se carecer de valor artístico, não poderá ser tutelada pela lei de direitos de autor"11.

Entretanto, há quem entenda que uma dupla proteção é possível, nesse sentido João da Gama Cerqueira se manifestou:

"Adotando a dualidade de proteção, tão combatida pelos autores franceses, a
lei, entretanto, não exclui a possibilidade da cumulação das leis sobre a
propriedade artística e sobre desenhos e modelos, em casos especiais. As
obras artísticas, e só elas, continuam protegidas pelo Código Civil e lei
especial; os desenhos e modelos industriais regem-se pela sua lei especial.
Nada impede, porém, que, tratando-se de obra artística aplicada a um objeto

\footnotetext{
${ }^{8}$ Art. $96, \S 3^{\circ}$ da Lei $n^{\circ} 9.279 / 96$.

9 SILVEIRA, Newton. Direito de autor no desenho industrial. Disponível na internet via http://www.newmarc.com.br/novo/index.asp?p=artigos.asp. Acesso em 29 de junho de 2006.

10 DANNEMANN, Siemsen, Bigler \& Ipanema Moreira. Comentários à lei da propriedade industrial e correlatos. Rio de Janeiro: Renovar, 2001, p. 199.

${ }^{11}$ SILVEIRA, Newton, obra citada.
}

Revista Brasileira de Direito Internacional, Curitiba, v.4, n.4, jul./dez.2006 
industrial ou posta no comércio como modelo industrial, seu autor invoque a proteção do Código Civil para a obra considerada sob a sua natureza intrínseca de obra de arte, e a da lei especial para o modelo. A reprodução de uma obra de arte por processos industriais ou a sua aplicação à indústria não a desnaturam, não lhe tiram o caráter artístico. Não se pode, pois, negar ao autor o reconhecimento do seu direito, nos moldes da lei civil, nem a proteção do desenho ou modelo, como tal, no campo da concorrência" ${ }^{12}$.

\section{DESENHOS INDUSTRIAIS NÃO REGISTRÁVEIS}

A Lei $n^{\circ}$ 9.279/96 enumera no art. 100 o que não é registrável como desenho industrial: I - o que for contrário à moral e aos bons costumes ou que ofenda a honra ou imagem de pessoas, ou atente contra liberdade de consciência, crença, culto religioso ou idéia e sentimentos dignos de respeito e veneração; Il - a forma necessária comum ou vulgar do objeto ou, ainda aquela determinada essencialmente por considerações técnicas ou funcionais.

$\mathrm{Na}$ primeira hipótese, essas exceções ficam sujeitas à percepção subjetiva do examinador. Na segunda hipótese somente o que não é determinado pelas características funcionais do objeto pode ser tido como ornamental, e assim suscetível de proteção como desenho industrial. Tal inciso foi assim esclarecido: "A forma mais comum ou vulgar (forma notória) de um objeto industrializado, como as formas convencionais de um clip, um prego ou uma cadeira, não é registrável. Da mesma maneira, a forma determinada essencialmente por considerações técnicas ou funcionais também não é registrável"13.

\section{PROCEDIMENTO}

Ao autor é assegurado o direito de obter registro de desenho industrial que the confira a propriedade. Salvo prova em contrário, presume-se 0 requerente legitimado a obter o registro.

\footnotetext{
${ }^{12}$ CERQUEIRA, João da Gama. Tratado da Propriedade Industrial. 2 ed. v. 1. São Paulo: Editora Revista dos Tribunais, 1982, p. 656.

${ }^{13}$ DI BLASI JUNIOR, Clésio Gabriel; GARCIA, Mario Augusto Soerensen; MENDES, Paulo

Parente Marques, obra citada, p. 191.
}

Revista Brasileira de Direito Internacional, Curitiba, v.4, n.4, jul./dez.2006 
Consoante o art. 104 da Lei $n^{\circ}$ 9.279/96, o pedido de registro de desenho industrial terá que se referir a um único objeto, permitida uma pluralidade de variações desde que se destinem ao mesmo propósito e guardem entre si a mesma característica distintiva preponderante, limitado cada pedido ao máximo de vinte variações.

O pedido de registro, nas condições estabelecidas pelo INPI, conterá: requerimento ${ }^{14}$; relatório descritivo, se for o caso; reivindicações, se for o caso; desenhos ou fotografias; campo de aplicação do objeto; e comprovante de pagamento da retribuição relativa ao depósito ${ }^{15}$.

Uma vez depositado o pedido de registro de desenho industrial, com satisfação dos requisitos legais, será automaticamente publicado e simultaneamente concedido o registro, expedindo-se o respectivo certificado ${ }^{16}$.

Se o depositante requerer, na ocasião do depósito, poderá ser mantido em sigilo o pedido por cento e oitenta dias contados da data do depósito. Em caso de solicitação de sigilo, o depositante poderá retirar o pedido em até noventa dias contados da data do depósito e tal pedido não servirá, no futuro, como referência de prioridade de um depósito posterior ${ }^{17}$.

No ato do depósito poderá ser requerida a reivindicação de prioridade, devendo ser comprovada por documento hábil, no momento do depósito ou em até noventa dias ${ }^{18}$.

Se o pedido não tiver os documentos formais que a lei exige, presentes no art. 101 da Lei, será formulada exigência que deverá ser respondida em sessenta dias, sob pena de arquivamento definitivo. Já se o pedido desatender o art. 100, será indeferido.

\footnotetext{
${ }^{14}$ Os itens do requerimento são apresentados no ato normativo $n^{\circ} 130$, de 05 de março de 1997, e são onze: 1. dados do depositante; 2. título do pedido de registro; 3.campo de aplicação; 4. informar se reivindica ou não prioridade; 5 . informar se requer sigilo na forma do art. 106 da LPI; 6. informação dos dados do(s) autor(s) do desenho industrial, conforme exemplificado no item 1, e se ele(s) requer(em) a não divulgação de seu(s) nome(s); 7. declaração de prioridade se houver; 8. declaração de divulgação anterior não prejudicial; 9. dados do procurador; 10. indicação dos documentos que serão anexados à petição e qual a quantidade de folhas; e 11. declaração de veracidade das informações prestadas contendo a assinatura, carimbo, local e data.

${ }^{15}$ Art. 101 da Lei $n^{\circ} 9.279 / 96$.

${ }^{16}$ Art. 106 da Lei $n^{\circ}$ 9.279/96.

${ }^{17}$ Art. 105 da Lei $n^{\circ} 9.279 / 96$.

${ }^{18}$ Art. 99 da Lei $n^{\circ}$ 9.279/96.
}

Revista Brasileira de Direito Internacional, Curitiba, v.4, n.4, jul./dez.2006 


\title{
5 VIGÊNCIA. PROTEÇÃO CONFERIDA PELO REGISTRO
}

A propriedade do desenho industrial adquire-se pelo registro validamente concedido ${ }^{19}$.

O registro vigorará pelo prazo de dez anos, contados da data do depósito, prorrogável por três períodos sucessivos de cinco anos cada. $O$ pedido de prorrogação deverá ser formulado durante o último ano de vigência do registro, instruído com o comprovante do pagamento da respectiva retribuição. Se o pedido de prorrogação não tiver sido formulado até o termo final da vigência do registro, o titular poderá fazê-lo nos cento e oitenta dias subseqüentes, mediante o pagamento da retribuição adicional ${ }^{20}$.

O registro confere ao seu titular o direito de impedir terceiro, sem o seu consentimento de fazer, de produzir, usar, colocar à venda, vender ou importar com estes propósitos o produto com o desenho industrial. Também o direito de impedir que terceiro contribua para que outros pratiquem os atos referidos.

Pode-se concluir que:

\begin{abstract}
“(...) a proteção é ao dado ornamental do produto, e não a qualquer funcionalidade; assim, ainda que as imagens e especificações do desenho indiquem um produto inteiro, a propriedade não abrange a utilidade industrial do produto, mas só a feição estética. (...) Assim, a proteção do desenho não se aplica aos atos praticados por terceiros não autorizados, em caráter privado e sem finalidade comercial, desde que não acarretem prejuízo ao interesse econômico do titular do registro; aos atos praticados por terceiros não autorizados, com finalidade experimental, relacionados a estudos ou pesquisas científicas, tecnológicas ou ornamentais e a produto fabricado de acordo com o desenho registrado que tiver sido colocado no mercado interno diretamente pelo titular do registro ou com seu consentimento". ${ }^{21}$
\end{abstract}

À pessoa que de boa fé, antes da data do depósito ou da prioridade do pedido de registro explorava seu objeto no país, será assegurado o direito de continuar a exploração sem ônus, na forma e condição anteriores. O direito conferido só poderá ser cedido juntamente com o negócio ou empresa, ou parte deste, que tenha direta relação com a exploração do objeto do registro, por alienação ou arrendamento. $O$ direito não será assegurado a pessoa que

\footnotetext{
${ }^{19}$ Art. 109 da Lei $n^{\circ} 9.279 / 96$.

${ }^{20}$ Art. $108, \S 1^{\circ}$ e $\S 2^{\circ}$ da Lei n० $9.279 / 96$.

${ }^{21}$ BARBOSA, Denis Borges, obra citada.
}

Revista Brasileira de Direito Internacional, Curitiba, v.4, n.4, jul./dez.2006 
tenha tido conhecimento do objeto do registro através de divulgação nos termos do depósito ou da prioridade reivindicada, desde que o pedido tenha sido depositado no prazo de seis meses contados da divulgação ${ }^{22}$.

\section{EXAME DE MÉRITO. NULIDADE}

A regra é que o exame de mérito dos desenhos industriais fique diferido até o momento que o próprio titular ou terceiros o requeiram. O INPI emitirá parecer de mérito, que, se concluir pela ausência de pelo menos um dos requisitos de originalidade ou novidade, servirá de fundamento para a instauração de processo de nulidade de registro ${ }^{23}$.

O processo de nulidade poderá ser instaurado de ofício ou mediante requerimento de qualquer pessoa com legítimo interesse, no prazo de cinco anos contados da concessão do registro, ou a qualquer tempo, no caso de exame solicitado pelo próprio titular. $O$ requerimento ou a instauração ex officio suspenderá os efeitos da concessão do registro se apresentada ou publicada no prazo de sessenta dias da concessão ${ }^{24}$.

O titular será intimado para se manifestar no prazo de sessenta dias contados da data da publicação. Havendo ou não manifestação, decorrido o prazo, o INPI emitirá parecer, intimando o titular e o requerente para se manifestarem no prazo comum de sessenta dias. Ao fim desse prazo, mesmo que não apresentadas as manifestações, o processo será decidido pelo Presidente do INPI, encerrando-se a instância administrativa; a lei não prevê recurso nessa instância ${ }^{25}$.

Judicialmente, a nulidade poderá ser argüida a qualquer tempo da duração do direito, pelo INPI ou por qualquer pessoa com legítimo interesse, assim como a qualquer tempo, como matéria de defesa. $\mathrm{O}$ juiz, preventiva ou incidentalmente, poderá determinar a suspensão dos efeitos do registro.

\footnotetext{
${ }^{22}$ Art. $110, \S 1^{\circ}, \S 2^{\circ}$ e $\S 3^{\circ}$ da Lei $n^{\circ} 9.279 / 96$.

${ }^{23}$ Art. 111 da Lei $n^{\circ} 9.279 / 96$.

${ }^{24}$ Art. $113, \S 1^{\circ}$ e $\S 2^{\circ}$ da Lei $n^{\circ} 9.279 / 96$.

${ }^{25}$ Arts. 114,115 e 116 da Lei $n^{\circ} 9.279 / 96$.
}

Revista Brasileira de Direito Internacional, Curitiba, v.4, n.4, jul./dez.2006 
Alguns autores, como Anali de Oliveira Anhuci, apontam serem inconciliáveis a antecipação de tutela do processo civil com o registro concedido pelo INPI sem exame de mérito:

\begin{abstract}
“(...) a forma de concessão do registro de desenho industrial, carente de exame apurado, torna o título um direito fragilizado. Como fonte de fundamentação à demanda específica, conduz à inviabilidade de formulação de pedido antecipatório. (...) o titular de registro de desenho industrial, em verdade, não tem em mãos título hábil a produzir prova inequívoca de seu direito, pois, no momento da concessão, não foi o seu pedido analisado com a ideal profundidade. (...) poderá se levantar que a aparente fraqueza do registro pode conduzir a situação injusta ao seu titular, que se verá obrigado a aguardar pelo julgamento definitivo do feito. (...) revelando-se no mínimo arriscada, se não inviável, a aplicação da tutela de cognição sumária aos processos que versam sobre registro de desenho industrial."26
\end{abstract}

\title{
7 EXTINÇÃO DO REGISTRO
}

O direito ao desenho industrial extingue-se pela expiração do prazo de vigência; pela renúncia de seu pela renúncia de seu titular; pela falta de pagamento da retribuição qüinqüenal; ou pela inobservância da regra de que o titular domiciliado no exterior deverá constituir e manter procurador devidamente qualificado e domiciliado no País, com poderes para representá-la administrativa e judicialmente, inclusive para receber citações ${ }^{27}$.

\section{DENOMINAÇÃO. LIMITES DA PROTEÇÃO}

A Europa é o local onde o instituto está mais difundido, começou a ser utilizado na identificação de vinho e hoje abrange diversos produtos.

$O$ art. 176 da Lei $n^{\circ}$ 9.279/96 classifica as indicações geográficas em indicação de procedência e em denominação de origem. Indicação de procedência é o nome geográfico de país, cidade, região ou localidade de seu território, que se tenha tornado conhecido como centro de extração, produção ou fabricação de determinado produto ou de prestação de determinado

\footnotetext{
${ }^{26}$ ANHUCl, Anali de Oliveira. Registro de desenho industrial e a antecipação de tutela. Disponível na internet via http://www.ibpi.org.br/. Acesso em 29 de junho de 2006.

${ }^{27}$ Art. 119 e incisos da Lei ${ }^{\circ}$ 9.279/96.
}

Revista Brasileira de Direito Internacional, Curitiba, v.4, n.4, jul./dez.2006 
serviço $^{28}$. Portanto, para a caracterização da indicação de procedência é suficiente a vinculação do produto ou serviço a um determinado espaço geográfico, independentemente de suas características e qualidades.

Enquanto que denominação de origem é o nome geográfico de país, cidade, região ou localidade de seu território, que designe produto ou serviço cujas qualidades ou características se devam exclusiva ou essencialmente ao meio geográfico, incluídos fatores naturais e humanos ${ }^{29}$. Assim, a denominação de origem se vincula as características e peculiaridades físicas e humanas existentes no local. Trata-se de um produto cujo modo de fabricação apresenta peculiaridades que o diferencia de outros da mesma natureza.

O Instituto Nacional de Propriedade Industrial ${ }^{30}$ informa que o reconhecimento de uma indicação geográfica é fruto do esforço de um grupo de produtores vinculados à região que se diferencia pelo fornecimento de determinado bem ou serviço. Uma vez reconhecida, a indicação geográfica somente pode ser utilizada pelo produtor ou pelo prestador de serviço que respeita as regras de produção ou prestação específica, o que pode vir a elevar o seu preço.

A proteção estender-se-á à representação gráfica ou figurativa da indicação geográfica, bem como à representação geográfica de país, cidade, região ou localidade de seu território cujo nome seja indicação geográfica ${ }^{31}$. Ou seja, ocorre o impedimento, por exemplo, de que fabricantes de uísque sediados fora da Escócia lancem mão da figura de tocadores de gaita de foles em seus rótulos ${ }^{32}$.

\footnotetext{
${ }^{28}$ Art. 177 da Lei $n^{\circ}$ 9.279/96. Como exemplo de indicação de procedência pode ser citada a região de Franca, no interior de São Paulo, por conta da fama que adquiriu na produção de calçados masculinos de boa qualidade, poderia vir a ser considerada uma indicação de procedência para calçados.

${ }^{29}$ Art. 178 da Lei $n^{\circ} 9.279 / 96$. Nessa categoria se enquadram os vinhos, dado que a qualidade das uvas e o beneficiamento do produto dependem das condições do meio ambiente, físico e humano, em que são produzidos. "Como exemplo desta influência temos o vinho do porto, elaborado unicamente com uvas colhidas em pequena região demarcada às margens do Rio Douro, em Portugal, cujo solo pedregoso e rico em xisto proporciona características únicas àquele vinho". (DANNEMANN, Siemsen, Bigler \& Ipanema Moreira, obra citada, p. 339)

30 INPI - Instituto Nacional de Propriedade Industrial. Disponível na internet via http://www.inpi.gov.br/. Acesso em 29 de junho de 2006.

${ }^{31}$ Art. 179 da Lei ${ }^{\circ} 9.279 / 96$.

32 DANNEMANN, Siemsen, Bigler \& Ipanema Moreira, obra citada, p. 339.
}

Revista Brasileira de Direito Internacional, Curitiba, v.4, n.4, jul./dez.2006 
Exceção a essa regra ocorre quando o nome geográfico se tornou de uso comum, designando produto ou serviço, nesse caso não será considerado indicação geográfica ${ }^{33}$. Exemplo disso é a palavra cheddar que passou a designar um tipo particular de queijo, o qual não é necessariamente feito em Cheddar, na Inglaterra. Outro exemplo, agora nacional, é o do queijo de minas, proveniente daquele estado brasileiro e hoje produzido em todo o país sob essa denominação.

\section{MARCAS E INDICAÇÕES GEOGRÁFICAS}

O art. 181 da Lei brasileira de Propriedade Industrial regula a relação entre marcas e indicações geográficas, prevendo que o nome geográfico que não constitua indicação de procedência ou denominação de origem poderá servir de elemento característico de marca para produtos ou serviços, desde que não introduza falsa procedência.

Essa tênue diferença entre marcas e indicações geográficas é esclarecida por Camila Serrano Giunchetti:

\footnotetext{
"A principal diferença entre as marca e indicações geográficas está na titularidade do direito subjetivo: aquelas conferem direitos individuais, consistentes basicamente na exclusividade de uso e gozo do registrante; já as indicações geográficas têm natureza coletiva, garantindo a todos os membros da comunidade o direito de uso, independentemente de qualquer autorização, registro ou filiação",34.
}

Ainda com relação a natureza coletiva das indicações geográficas é mister salientar que elas não são atribuíveis a uma pessoa física e jurídica e, sim, a todos os membros da coletividade que lá produzem de acordo com os padrões reconhecidos e aceitos por todos ${ }^{35}$.

Outro ponto é que os nomes ou figurações geográficas, não vinculados à origem de qualquer artigo ou serviço, podem ser usados como nome de

\footnotetext{
${ }^{33}$ Art. 180 da Lei $n^{\circ} 9.279 / 96$.

${ }^{34}$ GIUNCHETTI, Camila Serrano. Indicações geográficas: uma abordagem pragmática acerca de sua apropriação por comunidades tradicionais da Amazônia. CARVALHO, Patrícia Luciane. Propriedade Intelectual: estudos em homenagem à professora Maristela Basso. Curitiba: Juruá, 2005, p. 396.

${ }^{35}$ Idem, ibidem, p. 396.
}

Revista Brasileira de Direito Internacional, Curitiba, v.4, n.4, jul./dez.2006 
fantasia, e como tal registrados. Essas hipóteses são assim exemplificadas por Denis Borges Barbosa:

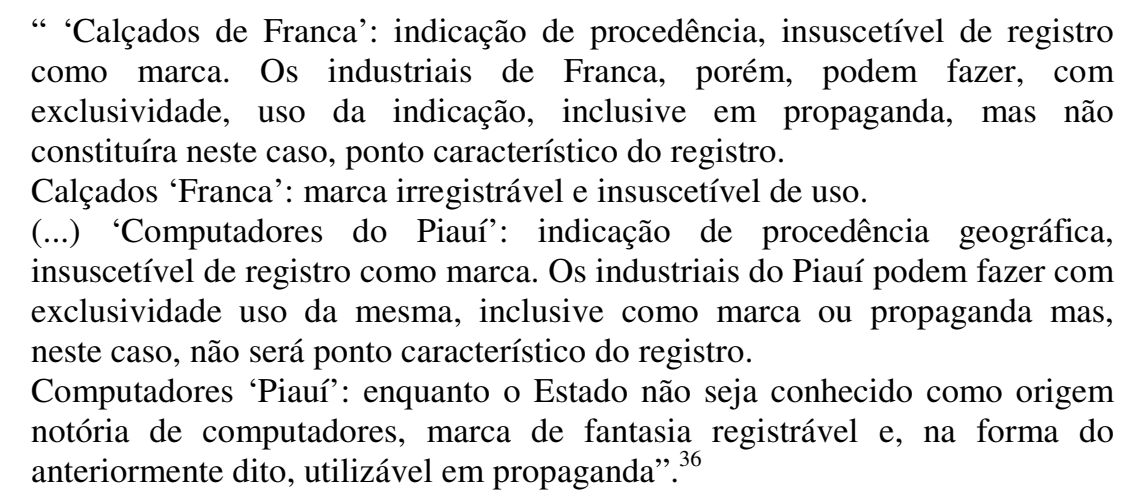

\section{PEDIDO DE REGISTRO DE INDICAÇÃO GEOGRÁFICA}

As condições de registrabilidade das indicações geográficas se encontram dispostas no Ato Normativo do INPI de $n^{\circ} 133$ de 23/04/1997, e na Resolução do INPI n 75 de 28/11/2000.

O registro de indicações geográficas, consoante o parágrafo único do art. $1^{\circ}$ da Resolução $n^{\circ} 75$ de 2000 , tem natureza declaratória.

Podem requerer o registro as associações, institutos e pessoas jurídicas representativas da coletividade legitimadas ao uso exclusivo do nome geográfico e estabelecidas no respectivo território, na qualidade de substitutos processuais.

O pedido de reconhecimento de indicação geográfica deverá ser requerido em formulário próprio do INPI, referir-se-á a um único nome geográfico, onde deverão ser discriminadas as informações sobre o nome geográfico; a descrição do produto ou serviço; e as características do produto ou serviço. Além desses requisitos deverão ser observados outros itens e anexados: instrumento hábil a comprovar a legitimidade do requerente; regulamento de uso do nome geográfico; instrumento oficial que delimita a área geográfica; etiquetas, quando se tratar de representação gráfica ou figurativa da denominação geográfica ou de representação geográfica de país, cidade,

${ }^{36}$ BARBOSA, Denis Borges. Indicações geográficas. Disponível na internet via http://denisbarbosa.addr.com/98.doc. Acesso em 29 de junho de 2006.

Revista Brasileira de Direito Internacional, Curitiba, v.4, n.4, jul./dez.2006 
região ou localidade do território; procuração outorgada ao representante do requerente, se for o caso, e; comprovante do pagamento da retribuição correspondente ${ }^{37}$.

Além desses documentos, o pedido de reconhecimento de uma indicação de procedência deve conter ainda: a) elementos que comprovem ter o nome geográfico se tornado conhecido como centro de extração, produção ou fabricação do produto ou de prestação do serviço; b) elementos que comprovem a existência de uma estrutura de controle sobre os produtores ou prestadores de serviços que tenham o direito ao uso exclusivo da indicação de procedência, bem como sobre o produto ou a prestação do serviço distinguido com a indicação de procedência; e c) elementos que comprovem estar os produtores ou prestadores de serviços estabelecidos na área geográfica demarcada e exercendo, efetivamente, as atividades de produção ou de prestação do serviço ${ }^{38}$.

Requisitos especiais também são exigidos quando se trata de reconhecimento do nome geográfico como denominação de origem: a) descrição das qualidades e características do produto ou do serviço que se devam, exclusiva ou essencialmente, ao meio geográfico, incluindo os fatores naturais e humanos; b) descrição do processo ou método de obtenção do produto ou do serviço, que devem ser locais, leais e constantes; c) elementos que comprovem a existência de uma estrutura de controle sobre os produtores ou prestadores de serviços que tenham o direito ao uso exclusivo da denominação de origem, bem como sobre o produto ou a prestação do serviço distinguido com a denominação de origem; e d) elementos que comprovem estar os produtores ou prestadores de serviços estabelecidos na área geográfica demarcada e exercendo, efetivamente, as atividades de produção ou de prestação do serviço ${ }^{39}$.

No caso de pedido de registro de nome geográfico já reconhecido como indicação geográfica no seu país de origem ou por entidades/organismos internacionais competentes, fica dispensada a apresentação dos documentos

\footnotetext{
${ }^{37}$ Art. $6^{\circ}$, incisos I ao VII da Resolução 75/00.

${ }^{38}$ Art. $7^{\circ}, \S 1^{\circ}$ da Resolução $75 / 00$.

${ }^{39}$ Art. $7^{\circ}, \S 2^{\circ}$ da Resolução 75/00.
}

Revista Brasileira de Direito Internacional, Curitiba, v.4, n.4, jul./dez.2006 
relativamente aos dados que constem do documento oficial que reconheceu a indicação geográfica, o qual deverá ser apresentado em cópia oficial, acompanhado de tradução juramentada ${ }^{40}$.

\section{PROCESSAMENTO DO PEDIDO}

O pedido de registro de indicação geográfica, primeiramente, será submetido ao exame formal, durante o qual poderão ser formuladas exigências para sua regularização, que deverão ser cumpridas no prazo sessenta dias, sob pena de arquivamento definitivo do pedido de registro.

Concluído o exame formal do pedido de registro será o mesmo publicado, para apresentação de manifestação de terceiros no prazo de sessenta dias. Decorrido o prazo fixado sem que tenha sido apresentada manifestação de terceiros ou, se apresentada esta, findo o prazo para contestação do requerente, será proferida decisão confirmando ou negando reconhecimento à indicação geográfica. A decisão que reconhecer a indicação geográfica encerra a instância administrativa.

Se indeferido o pedido cabe pedido de reconsideração ao Presidente do INPI, no prazo de sessenta dias. A decisão que reconhecer a indicação geográfica encerra a instância administrativa.

\subsection{CASOS DE INDICAÇÕES GEOGRÁFICAS NO BRASIL}

No Brasil o INPI concedeu o primeiro registro de indicação geográfica em janeiro de 2005. Foi uma identificação de procedência, "Vale dos Vinhedos", para identificar vinhos finos produzidos nessa região. Analisando esse primeiro registro de indicação geográfica Camila Serrano Giunchetti pondera:

\footnotetext{
"Mesmo com inovações comprovadas e com características determinantes da região delimitada, Aprovale e Embrapa decidiram solicitar inicialmente ao INPI o reconhecimento da região como uma indicação de procedência, ou seja, uma área geográfica simplesmente reconhecida pela produção e
}

\footnotetext{
${ }^{40}$ Art. $8^{\circ}$ da Resolução 75/00.
}

Revista Brasileira de Direito Internacional, Curitiba, v.4, n.4, jul./dez.2006 
comercialização de vinhos finos. Essa estratégia foi adotada com a intenção de fortalecer as regras de controle de qualidade. Com a consolidação da indicação de procedência e a certeza da qualidade diferenciada de seus produtos, a Aprovale poderá requerer o reconhecimento da área como uma denominação de origem". 41

Outra indicação de procedência genuinamente brasileira foi a concedida aos produtores de café da região do "Cerrado Mineiro" em março de 2005. O "Cerrado Mineiro" é a primeira região demarcada de café do Brasil, sendo, também, oficialmente, a primeira indicação geográfica de café do mundo ${ }^{42}$.

A cachaça foi um outro caso interessante. Em 2001, com o aumento das vendas no exterior da aguardente de cana-de-açúcar destilada no Brasil, intensificou-se o interesse em proteger o termo "cachaça" internacionalmente. Diante das pressões e interesses o governo brasileiro publicou o Decreto 4.062, de 21 de dezembro de 2001, o qual define as expressões "cachaça", "Brasil" e "cachaça do Brasil" como indicações geográficas e dá outras providências.

Pelo decreto, o nome "cachaça" constitui indicação geográfica para os efeitos, no comércio internacional, do art. 22 de TRIP's. O nome geográfico "Brasil" constitui indicação geográfica para cachaça, sem prejuízo de usá-lo em outros produtos e serviços.

O decreto prossegue afirmando serem essas expressões protegidas de uso restrito dos produtores estabelecidos no país. O decreto não foi a maneira mais correta de lidar com a situação, talvez fosse necessário a alteração da Lei de Propriedade Industrial, para conseguir abarcar o termo "cachaça", que não é o nome do local de origem. E agora, mesmo após a vigência do decreto, permanece a dúvida se "cachaça" deve ser considerada indicação de procedência ou denominação de origem. Essa situação exposta é analisada por Camila Serrano Giunchetti:

“(...) o decreto foi uma solução precária para resolver imediatamente o problema das exportações brasileiras da bebida. O procedimento mais adequado teria sido a alteração da Lei de propriedade Industrial, incluindo nela, (...) a possibilidade de registro de termos que não sejam necessariamente o nome do local de origem do produto, no rol dos termos

\footnotetext{
${ }^{41}$ GIUNCHETTI, Camila Serrano, obra citada, p. 404.

42 Informação disponível na internet via http://www.cafedocerrado.org/br/index.php.
}

Revista Brasileira de Direito Internacional, Curitiba, v.4, n.4, jul./dez.2006 
passíveis de proteção. Outra alteração necessária seria a flexibilização dos critérios de delimitação geográfica da área, para abrabger produtores de todo o país. Dessa forma, o órgão competente pelo reconhecimento de indicações geográficas, o INPI, poderia apreciar o pedido de registro de indicações geográficas que usem termos não correspondentes ao local de origem, como "cachaça", por exemplo, e abranjam todo o território nacional, conferindo, assim, maior legitimidade e segurança, tanto interna como externamente, ao reconhecimento de indicações geográficas deste tipo"43.

\section{INDICAÇÕES GEOGRÁFICAS E POPULAÇÕES TRADICIONAIS}

A expressão populações tradicionais será usada em uma acepção ampla englobando os povos indígenas ${ }^{44}$, os quilombolas ${ }^{45}$, além, das populações que desenvolveram relações próprias e diferenciadas com a natureza, como os pescadores, os castanheiros, as quebradeiras de coco babaçu, entre outros, populações em que o território é um elemento essencial.

A Lei brasileira de Propriedade Industrial permite o reconhecimento de indicações geográficas para produtos artesanais ou industrializados, portanto, "o artesanato de povos indígenas e polpas de frutas nativas processadas e congeladas, e serviços, como o turismo" ${ }^{\circ 6}$ podem ser registrados. Isso ocorre porque a lei brasileira não restringe o reconhecimento das indicações geográficas a produtos alimentícios ou agrícolas.

Um exemplo de um produto tipicamente brasileiro, que deveria ser protegido para preservar suas características regionais e culturais é 0 artesanato do capim dourado.

\footnotetext{
${ }^{43}$ GIUNCHETTI, Camila Serrano, obra citada, p. 406.

44 A Constituição Federal reconheceu a importância do solo para os povos indígenas, assegurando direitos originários sobre os territórios que tradicionalmente ocupam. Assim está previsto no art. 231"São reconhecidos aos índios sua organização social, costumes, línguas, crenças e tradições, e os direitos originários sobre as terras que tradicionalmente ocupam, competindo à União demarcá-las, proteger e fazer respeitar todos os seus bens. $\S 1^{\circ}$ - são terras tradicionalmente ocupadas pelos índios as por eles habitadas em caráter permanente, as utilizadas para suas atividades produtivas, as imprescindíveis à preservação dos recursos ambientais necessários a seu bem estar e às necessárias a sua reprodução física e cultural, segundo seus usos, costumes e tradições. $\S 2^{\circ}$ - as terras tradicionalmente ocupadas pelos índios destinam-se a sua posse permanente, cabendo-lhes o usufruto exclusivo das riquezas do solo, dos rios e dos lagos nelas existentes."

${ }^{45} \mathrm{O}$ art. 68 dos Atos das Disposições Constitucionais Transitórias dispõe "aos remanescentes das comunidades dos quilombos que estejam ocupando suas terras é reconhecida a propriedade definitiva, devendo o Estado emitir-lhes os títulos respectivos".

${ }^{46}$ GIUNCHETTI, Camila Serrano, obra citada, p. 409.
} 
O capim dourado é uma planta que só existe na região do Jalapão em Tocantins, precisamente na comunidade de Mumbuca. As artesãs locais, remanescentes dos antigos quilombos, fazem com a palha bolsas, cestos, cintos, pulseiras, bandejas, descansos e chaveiros, os quais ficam com a aparência e o impressionante brilho do ouro, utilizam para isso técnicas passadas de geração em geração. Essas peças, que são compradas a preços muito baixos, ao serem revendidas no exterior podem alcançar a cifra de até US\$ 500,00 (quinhentos dólares). A proteção deste artesanato traria a possibilidade de preservar as técnicas de produção local, além de trazer progresso econômico, para uma região que ainda enfrenta sérios problemas sociais como a desnutrição e a falta de saneamento básico ${ }^{47}$.

A grande questão atualmente é a sustentabilidade ambiental, cultural e econômica do território das populações tradicionais, isso "inclui a gestão sustentável de seus recursos naturais e a continuidade de suas práticas socioculturais coletivas, e de seus usos, costumes e tradições, consagradores da sua diversidade cultural”48.

Destarte, as indicações geográficas podem servir de instrumentos para a diferenciação dos produtos gerados pelas populações tradicionais no mercado, agregando-lhes valor.

\section{CONCLUSÃO}

A atual Lei de Propriedade Industrial procurou acompanhar a natureza fugaz, transitória dos desenhos industriais, o que fez com que o exame de

\footnotetext{
47 ZARUR, Fernando. O brilho do capim dourado. Disponível na internet via http://www.brasiloeste.com.br/noticia/1182/jalapao-capim-dourado. Acesso em 29 de junho de 2006.

${ }_{48}$ SANTILLI, Juliana. As indicações geográficas e as territorialidades específicas das populações tradicionais, povos indígenas e quilombolas. LAGES, Vinícius; LAGARES, Lea; BRAGA, Christiano Lima (org). Valorização de produtos com diferencial de qualidade $e$ identidade: indicações geográficas e certificações para competitividade nos negócios. Brasília: Sebrae, 2005, p. 197.
}

Revista Brasileira de Direito Internacional, Curitiba, v.4, n.4, jul./dez.2006 
mérito fosse suprimido em um momento inicial, visando agilizar o processo. Fato que pode chegar a situações indesejadas.

Já as indicações geográficas se mostram como sinais distintivos que agregam valor ao produto ou serviço e geram riqueza. Atestam a originalidade, e para o consumidor é uma garantia de identidade própria e inconfundível, por essas características os consumidores podem se sentir estimulados a pagar um preço maior.

Um obstáculo que surge, e agora de natureza cultural, é que aqui no Brasil não ocorre a valorização de produtos diferenciados. Portanto, algum esforço deve ser feito no sentido de esclarecer os consumidores a respeito dos sinais distintivos.

Por fim, cumpre lembrar que o reconhecimento de uma indicação geográfica apenas confirma a realidade. Algumas regiões, que poderiam se beneficiar do reconhecimento da indicação geográfica, não conseguem porque apresentam estruturas arcaicas, que inviabilizam a gestão das indicações geográficas. E o reconhecimento apenas ocorre se houver autogestão, controle da qualidade e fiscalização da produção. Mudanças, tanto legislativas quanto de políticas públicas, devem ser realizadas para se adequarem a realidade brasileira.

\section{REFERÊNCIAS}

ANHUCI, Anali de Oliveira. Registro de desenho industrial e a antecipação de tutela. Disponível na internet via http://www.ibpi.org.br/. Acesso em 29 de junho de 2006.

BARBOSA, Denis Borges. Indicações geográficas. Disponível na internet via http://denisbarbosa.addr.com/98.doc. Acesso em 29 de junho de 2006.

Proteção dos Modelos de Utilidade e do Designs. Disponível na internet via http://denisbarbosa.addr.com/127.doc. Acesso em 29 de junho de 2006.

CAFÉ DO CERRADO. Disponível na internet via http://www.cafedocerrado.org/br/index.php. Acesso em 29 de junho de 2006.

Revista Brasileira de Direito Internacional, Curitiba, v.4, n.4, jul./dez.2006 
CERQUEIRA, João da Gama. Tratado da Propriedade Industrial. 2 ed. V. 1. São Paulo: Editora Revista dos Tribunais, 1982.

DANNEMANN, Siemsen, Bigler \& Ipanema Moreira. Comentários à lei da propriedade industrial e correlatos. Rio de Janeiro: Renovar, 2001

DI BLASI JUNIOR, Clésio Gabriel; GARCIA, Mario Augusto Soerensen; MENDES, Paulo Parente Marques. A propriedade industrial: os sistemas de marcas, patentes e desenhos industriais a partir da Lei $n^{\circ} 9.279$, de 14 de maio de 1996. Rio de Janeiro: Forense, 1996.

GIUNCHETTI, Camila Serrano. Indicações geográficas: uma abordagem pragmática acerca de sua apropriação por comunidades tradicionais da Amazônia. CARVALHO, Patrícia Luciane. Propriedade Intelectual: estudos em homenagem à professora Maristela Basso. Curitiba: Juruá, 2005, p. 391-420.

INPI - Instituto Nacional de Propriedade Industrial. Disponível na internet via http://www.inpi.gov.br/.

PIMENTEL, Luiz Otávio. Propriedade intelectual e universidade: aspectos legais. Florianópolis: Boiteux, 2005.

SANTILLI, Juliana. As indicações geográficas e as territorialidades específicas das populações tradicionais, povos indígenas e quilombolas. LAGES, Vinícius; LAGARES, Lea; BRAGA, Christiano Lima (org). Valorização de produtos com diferencial de qualidade e identidade: indicações geográficas e certificações para competitividade nos negócios. Brasília: Sebrae, 2005.

SILVEIRA, Newton. Direito de autor no desenho industrial. Disponível na internet via http://www.newmarc.com.br/novo/index.asp?p=artigos.asp. Acesso em 29 de junho de 2006.

ZARUR, Fernando. O brilho do capim dourado. Disponível na internet via http://www.brasiloeste.com.br/noticia/1182/jalapao-capim-dourado. Acesso em 29 de junho de 2006.

Revista Brasileira de Direito Internacional, Curitiba, v.4, n.4, jul./dez.2006 